\title{
Usefulness of a New Gelatin Glue Sealant System for Dural Closure in a Rat Durotomy Model
}

\author{
Hisashi KAWAI, ${ }^{1}$ Ichiro NAKAGAWA, ${ }^{1}$ Fumihiko NiSHIMURA, ${ }^{1}$ \\ Yasushi MOTOYAMA, ${ }^{1}$ Young-Su PARK, ${ }^{1}$ Mitsutoshi NAKAMURA, ${ }^{1}$ \\ Hiroyuki NAKASE, ${ }^{1}$ Shuko SUZUKI, ${ }^{2}$ and Yoshito IKADA ${ }^{2}$ \\ Departments of ${ }^{1}$ Neurosurgery and ${ }^{2}$ Biomedical Engineering, Nara Medical University, \\ Kashihara, Nara
}

\begin{abstract}
Watertight dural closure is imperative after neurosurgical procedures, because inadequately treated leakage of cerebrospinal fluid (CSF) can have serious consequences. We used a rat durotomy model to test the usefulness of a new gelatin glue as a dural sealant in a rat model of transdural CSF leakage. All rats were randomly divided into one of the following three treatment groups: no application (control group: $N=18$ ), application of fibrin glue (fibrin glue group: $\mathrm{N}=18$ ), and application of the new gelatin glue (new gelatin glue group: $\mathrm{N}=18$ ). The craniotomy side was re-opened, and CSF leakage was checked and recorded at 1,7 , and 28 days postoperatively. The new gelatin glue was adequate for stopping CSF leakage; no leakage was observed at postoperative days 1 or 7 , and leakage was observed in only one rat at postoperative day 28. This result was statistically significant when compared to the control group $(P=0.002, P=0.015$, $P=0.015$, respectively). The pathologic score of the new gelatin group was not different from that of the control or fibrin glue groups. We conclude that our new gelatin glue provides effective watertight closure 1,7 , and 28 days after operation in the rat durotomy model.
\end{abstract}

Key words: cerebrospinal fluid leak, dural sealant system, gelatin glue

\section{Introduction}

Appropriate closure of the dura is very important in preventing cerebrospinal fluid (CSF) leakage in neurosurgical practice, as the dura constitutes a barrier on the brain surface. Although dural suturing remains the most frequently used method of closure, suture techniques are difficult to perform, particularly when defects are in relatively inaccessible areas or surrounded by friable dura. This has led some surgeons to advocate the use of various other techniques ${ }^{1-5)}$ including fibrin glue, ${ }^{6,7)}$ and hydrogel dural sealants. ${ }^{8)}$ These have all been used to achieve dural closure and/or reinforcement, but an effective dural sealant is still needed because these commercially available sealants are limited by low bonding strength, viral transmission, and troublesome preparation..$^{9,10)}$

To tackle these surgical problems, we created a sealant system using a common biomaterial,

Received January 7, 2014; Accepted April 8, 2014 gelatin. In medical applications, gelatin has been extensively used for pharmaceutical capsules, drug delivery systems, homeostatic agents [such as Gelfoam ${ }^{\circledR}$ (Pfizer, New York, USA) and Floseal ${ }^{\circledR}$ (Baxter Healthcare Corporation, Fremont, California, USA)], and surgical adhesives [such as GRF ${ }^{\circledR}$ (Cardial, Technopole, Saint-Etienne, France) and Bioglue ${ }^{\circledR}$ (CryoLife, Inc., Kennesaw, Georgia, USA)]. The gelatin glue used in our sealant system consists of $26 \mathrm{wt} \%$ gelatin and $1 \mathrm{wt} \%$ glutaraldehyde (GA) solutions and exhibits higher bonding strength and lower cytotoxicity than commercially available GRF ${ }^{\circledR}$ and Bioglue ${ }^{\circledast}$. In the present study, we evaluate the usefulness of this gelatin glue for preventing CSF leakage and tissue adhesions and compare it to an existing dural closure sealant system (fibrin glue).

\section{Materials and Methods}

This study was approved by the Advanced Medical Research Center of Nara Medical University in Japan. Surgical procedures were conducted under 
routine sterile techniques. All procedures in this study were performed by one neurosurgeon.

Gelatin was supplied by Nitta Gelatin Co. Ltd., Osaka. It was extracted from porcine skin to have an isoelectric point of 5. Phosphate-buffered saline (-), $25 \mathrm{wt} \%$ GA solution, 3-methyl-2-benzo-thiazoline hydrazone hydrochloride, and Dulbecco's modified Eagle medium were purchased from Wako Pure Chemical Inc., Osaka. Bovine serum albumin was purchased from Sigma-Aldrich (St. Louis, Missouri, USA). All reagents were used as obtained. Fibrin glue (Beriplast ${ }^{\circledR}$, CSL Behring, Victoria, Australia) was purchased from Wakenyaku Co. Ltd., Osaka. Doubly distilled water was used for all preparations. Gelatin and GA (1\%) solutions were preheated to $45^{\circ} \mathrm{C}$, and with the aid of an application device, these solutions were applied to the dura mater simultaneously with rubbing so that they mixed well, penetrated into the suture holes, and dried in 5 minutes. ${ }^{11)}$

\section{Surgical Procedure}

Male Wistar ST rats (8 weeks old) were housed at room temperature and fed the standard rat chow. No animal had any focal deficit before surgery. After pre-determined periods of time, rats were anesthetized with intraperitoneal administration of $30 \mathrm{mg} / \mathrm{kg}$ body weight sodium pentobarbital (Somnopentyl, Kyoritsu Seiyaku, Tokyo). The right frontoparietal area was shaved and treated with $100 \%$ ethyl alcohol. Rats were mounted in a stereotactic frame, and a linear skin incision was made in the right frontoparietal region. The muscle was dissected and reflected laterally, and an oval bone flap was raised with a highspeed drill under an operating microscope, avoiding brain injury (including subarachnoid hemorrhage). The dura mater was carefully kept intact during this procedure, then opened transversely for $3 \mathrm{~mm}$. Several areas of the arachnoid were also incised to allow CSF leakage. After the confirmation of homeostasis, the rats were randomly divided into the following three treatment groups: Control group, i.e., sham-operated group ( $\mathrm{N}=18)$; fibrin glue group, in which fibrin glue was applied to the opened dura $(\mathrm{N}=18)$; and gelatin glue group, in which gelatin glue was applied to the opened dura $(\mathrm{N}=$ 18). After each sealant was applied and allowed to dry for 5 minutes, the surgical area was closed with 3-0 silk, and the rats returned to individual cages. At 1,7 , and 28 days after surgery, each rat was anesthetized again as described above. The surgical site (the right frontoparietal region) was re-opened carefully. Granulation tissue over the craniectomy area was preserved as much as possible to avoid an occurrence of new CSF leakage associated with re-opening procedures. An observer blind to the rat's group recorded CSF leakage by visual confirmation. Twenty-eight days after surgery, histopathological evaluation was performed as described below.

\section{Histopathology}

After the visual evaluation on the 28th day, the rats were killed by intraperitoneal injection of an overdose of sodium pentobarbital $(300 \mathrm{mg} / \mathrm{kg})$. The brains were then perfused transcardially with $0.9 \%$ $\mathrm{NaCl}$ solution; the brain and skull were carefully taken out and decalcified, fixed in $10 \%$ buffered formaldehyde solution for 48 hours, and then blocked into 3-mm thick coronal sections using a brain slicer. All blocks were embedded in paraffin. One 4- $\mu$ m thick section taken from the center of the visible infarct using a microtome was stained with hematoxylin and eosin (HE). A veterinary pathologist blind to the brain's group diagnosed the sample after histological analysis.

The grading system used for semiquantitative evaluation was modified from the histological evaluation criteria of Ozisik et al. ${ }^{12)}$ and Lasa et al., ${ }^{13)}$ whereas the histopathologic changes in the leptomeninges and dura were semiquantitatively scored according to cell type and severity of inflammatory cell infiltration, granulation, deposition of collagen, and neovascularization (Table 1). These features were semiquantitatively scored from +1 to +5 by a pathologist.

Table 1 The grading system used for quantifying histopathology

\begin{tabular}{lccccc}
\hline Criteria/score & 1 & 2 & 3 & 4 & 5 \\
\hline Cell types & $\begin{array}{c}\text { No cell/few } \\
\text { inflammatory cells }\end{array}$ & $\begin{array}{c}\text { Inflammatory cells } \\
\text { and few fibroblasts }\end{array}$ & $\begin{array}{c}\text { Moderate fibroblast and } \\
\text { inflammatory cells }\end{array}$ & $\begin{array}{c}\text { Fibroblast } \\
\text { dominancy }\end{array}$ & $\begin{array}{c}\text { Few } \\
\text { fibroblasts }\end{array}$ \\
Granulation & None & Thin layer & Moderate thickness & Thick & Thick \\
Collagen deposit & None & Few fibers & Moderate fibers & $\begin{array}{c}\text { Intensive } \\
\text { fibers }\end{array}$ & $\begin{array}{c}\text { Dense-organized } \\
\text { fibers }\end{array}$ \\
Vascularization & None & Few new & Moderate capillaries & Dense & Dense capillary \\
& & capillaries & & network \\
\hline
\end{tabular}




\section{Statistical analyses}

Statistical analysis consisted of a standard $\chi^{2}$ test, and $\mathrm{P}<0.05$ was accepted as statistically significant. All statistical comparisons were performed using the Sigma-Stat software (Jandel Scientific, Erkrath, Germany).

\section{Results}

All animals survived until the scheduled second surgery. No treatment-related clinical observations, neurologic effects, body weight changes, or clinical pathology changes were noted. On postoperative day 1 , CSF leakage was observed in 6 of $6(100 \%)$ control group rats, 1 of 6 (17\%) fibrin glue group rats, and 0 of $6(0 \%)$ new gelatin glue group rats (Fig. 1A). The corresponding values were 5 of 6 $(83 \%), 2$ of $6(33 \%)$, and 0 of $6(0 \%)$ rats on postoperative day 7 (Fig. 1B) and 6 of $6(100 \%), 2$ of $6(33 \%)$, and 1 of $6(17 \%)$ on postoperative day 28 (Fig. 1C). Compared to the control group, the gelatin glue group showed significantly improved sealing at postoperative days 1,7 , and $28(\mathrm{P}=0.002, \mathrm{P}=$ $0.015, \mathrm{P}=0.015$, respectively). The fibrin glue group failed to show a significant sealing effect compared to the control group at postoperative days 7 and 28 .

Histologically, in the control group, inflammatory cells penetrated into the dural tissue and were encapsulated by a thick fibrocellular layer. Infiltration of histiocytes, lymphocytes, and fibroblasts was observed. The operated dural surface had been replaced by a thick fibrous tissue, with a slight infiltration of lymphocytes (Fig. 2A). In the fibrin glue group, the fibrin glue side showed a trend towards infiltration of lymphocytes (Fig. 2B). In the gelatin glue group, the gelatin glue had penetrated into the dural issue, and a layer of mesothelial cells covered the residual glue. The gelatin glue had degraded and converted to fibrous tissue, but no histological evidence of CSF leakage was observed. Infiltration of lymphocytes and fibroblasts was observed around the gelatin glue. No necrotic tissue or hemorrhage was evident (Fig. 2C). The results of the semiquantitative analyses of the histopathologic findings 28 days after surgery are summarized in Table 2. The scores were obtained by summing up the positive (+) counts of each histopathologic criterion that was evaluated and scored for each sample. Higher (+) scores meant increased tissue granulation, and greater deposition and maturation of collagen. In addition, with higher (+) scores, polymorphonuclear leukocyte infiltration decreased and fibroblast accumulation increased. A score of +5 signified the near absence of cell infiltration coinciding with well-formed collagen deposits. Therefore, a high

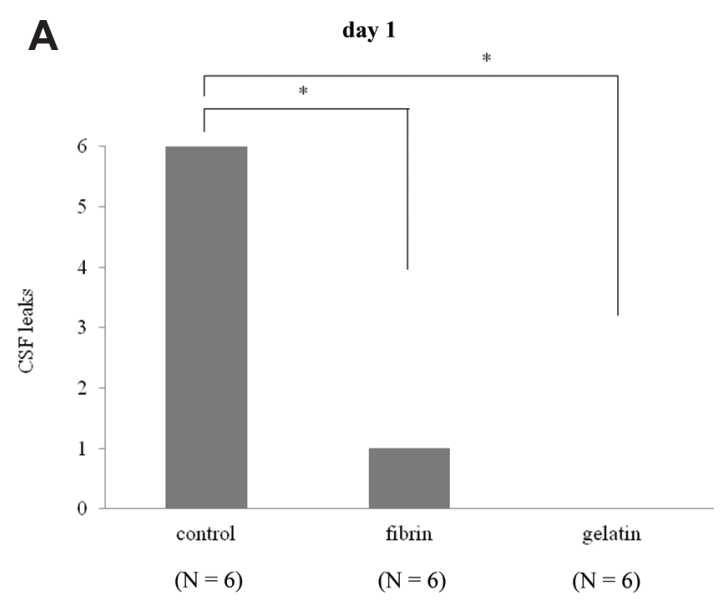

B day 7
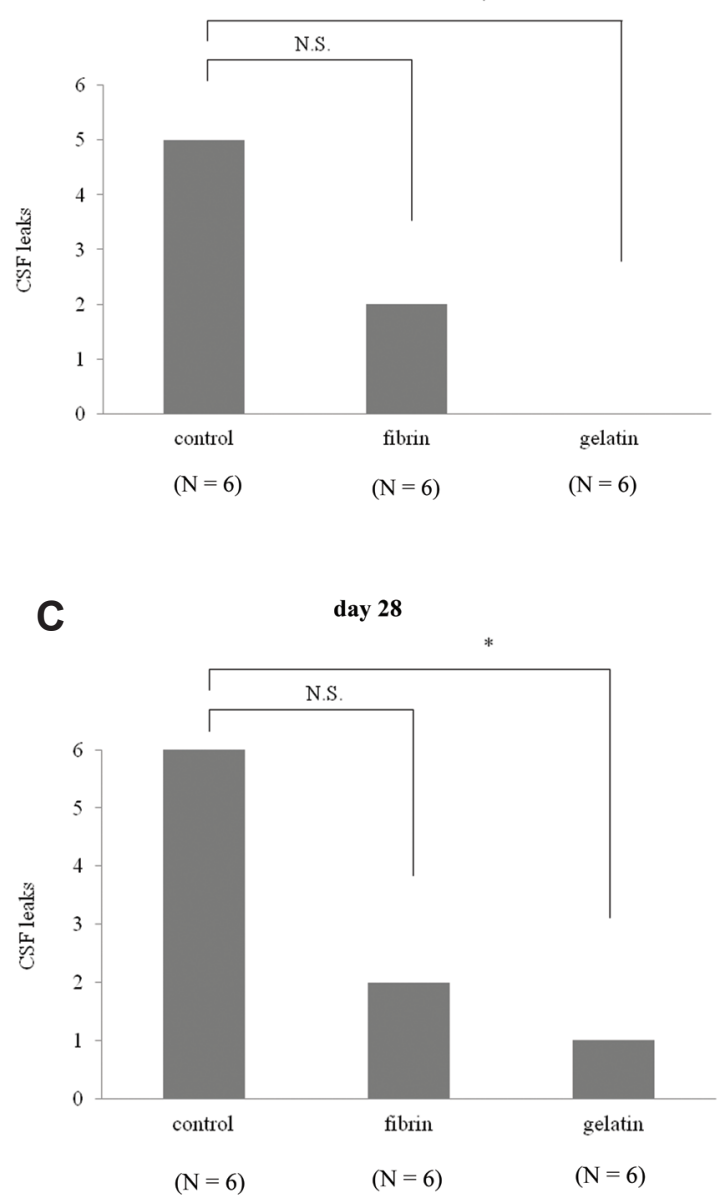

Fig. 1 The cerebrospinal fluid (CSF) leakage ratio at 1 day (A), 7 days (B), and 28 days (C) after surgery. The gelatin glue group showed a more significant sealing effect than the control group on all 3 days, whereas the fibrin glue group showed a significant sealing effect compared to the control group only on day 1 . N.S.: not significant, ${ }^{*} \mathbf{P}<\mathbf{0 . 0 5}$. 

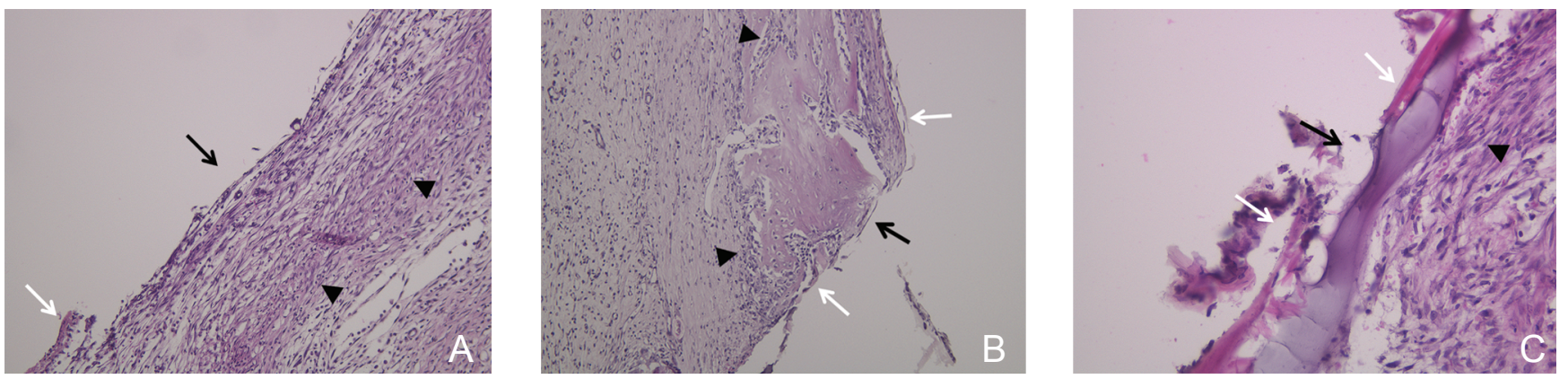

Fig. 2 A: Photomicrograph showing thick fibrous tissue (arrowhead), with a slight infiltration of lymphocytes in the control (black arrow; dural defect, white arrow; dural edge, original magnification $\times 200$ ). B: Showing mixed inflammatory cell infiltration (arrowhead) surrounding the fibrin glue (black arrow; dural defect, white arrow; dural edge, original magnification $\times 200$ ). C: Indicating fibroblastic activity (arrowhead) around the gelatin glue (black arrow; dural defect, white arrow; dural edge, original magnification $\times 400$ ).

Table 2 Histopathologic findings

\begin{tabular}{lcccc}
\hline $\begin{array}{l}\text { Groups/his- } \\
\text { topathologic } \\
\text { criteria }\end{array}$ & $\begin{array}{c}\text { Cell } \\
\text { types }\end{array}$ & Granulation & $\begin{array}{c}\text { Collagen } \\
\text { deposit }\end{array}$ & Vascularization \\
\hline Control & $20(+)$ & $20(+)$ & $19(+)$ & $23(+)$ \\
Fibrin glue & $17(+)$ & $19(+)$ & $21(+)$ & $20(+)$ \\
Gelatin glue & $23(+)$ & $24(+)$ & $18(+)$ & $19(+)$ \\
\hline
\end{tabular}

The total scores of each histopathological criterion were obtained by summing up the (+) counts of each brain sample that was evaluated and scored for each of the four criteria.

(+) count might have better attachment between the dura-galea graft. CSF leakage was expected to be less $(+)$ at the 28th postoperative day. ${ }^{12)}$ The data presented here indicate that the dural sealing properties of the tissue adhesives do not completely correlate with the histopathologic changes of the surrounding tissue.

\section{Discussion}

In the present study, a newly developed gelatin glue was used as a dural closure sealant to prevent CSF leakage in a rat durotomy model. This gelatin glue compares favorably as a sealant with fibrin glue at 1 and 7 days after surgery. Unlike the fibrin glue, this gelatin glue prevents CSF leakage significantly better than unglued controls at 28 days post-surgery. Further support for the present results comes from Suzuki and Ikada, who reported that the bursting water pressure of the new gelatin glue was significantly higher than that of the fibrin glue when applied by rubbing and spraying in a rat cecum abrasion model. ${ }^{11)}$ They reported higher bonding strength of gelatin and GA $(1 \%)$ solutions. The bonding strength of gelatin glue showed $144 \mathrm{gf} / \mathrm{cm}^{2}$, whereas that of fibrin glue was $48 \mathrm{gf} / \mathrm{cm}^{2}$. Furthermore, they demonstrated remarkably higher water sealing effect of gelatin glue on the expanded polytetrafluoroethylene vascular prosthesis. The burst water pressure of gelatin glue was $400 \mathrm{mmHg}$ by rubbing, whereas that of fibrin glue was $140 \mathrm{mmHg}$ with rubbing. ${ }^{11)}$ These results can be explained by the unique molecular characteristics of gelatin. It is present in solution primarily as random chains that entangle with each other, resulting in strong adhesion. Furthermore, the gelatin molecule consists of a variety of co-monomers that involve hydrophobic, polar, and negatively/positively charged amino acids, which facilitate particular interactions with the surface to be glued..$^{11,14)}$

The appeal of the new gelatin glue as a dural sealant is compelling when its properties are compared to those of other available dural closure/sealing techniques. Previous studies documenting the effectiveness of fibrin glue and other tissue adhesives for sealing CSF leakage were performed on relatively small dural defects. ${ }^{15}$ Though the use of fibrin glue in neurosurgical practice is well established, it has some shortcomings, including possible viral transmission, low adhesive strength, difficult preparation, and high cost. ${ }^{9,10)}$ In addition, fluid collection has been reported in $26 \%$ of the cases in which fibrin glue was used. ${ }^{9)}$ Further complications include the requirement of dry surfaces to polymerize, insufficient mechanical strength, and difficult handling/ working conditions. ${ }^{10)}$ To ensure optimal adhesion for the fibrin glue group, we took care to dry the dura mater surfaces as much as possible. However, the fibrin glue was still less adhesive than gelatin glue. A recently developed, synthetic polyethylene glycol-based hydrogel sealant is increasingly being used to facilitate watertight repair of cranial and 
spinal dural defects and prevent CSF leakage. ${ }^{16-21)}$ It has been demonstrated to be both safe and effective in clinical studies, but it shares the same drawbacks as fibrin glue. ${ }^{21)}$ Additionally, the hydrogel absorbs fluid from the body, increasing its volume up to $50 \%$ and leading to a risk of compression of neural elements. ${ }^{21,22)}$ In fact, a hematoma enveloped by the hydrogel has also been reported. ${ }^{23)}$

On the other hand, the gelatin gel, despite being resolved in living tissue, possesses some desirable properties as a dural sealant. It provided a superior dural closure, remaining watertight for at least 28 days. Interestingly, we did not observe a relationship between CSF leakage and histopathology, but reports on the histopathology of tissue adhesives are themselves conflicting. Although some previous studies described enhanced local accumulation of mononuclear cells and increased angiogenesis close to the wound by fibrin glue, ${ }^{24,25)}$ other studies have shown reduced severity of postsurgical intraabdominal adhesion in rats. ${ }^{14,26)}$ This might be due to the formation of granulation tissue and deposition of extracellular matrix, a process that is affected by numerous tissue-dependent and environmental factors. The histopathological evaluation showed the gelatin group formed collagen fibers less intensively than the fibrin group. An increased inflammatory response with dominant polymorphonuclear leukocyte infiltration still appeared to persist on the 7th postoperative day. The weaker dural seal in the fibrin group, as evidenced by a higher CSF leakage ratio than the gelatin glue group, may be a result of secondary healing with fragile granulation tissue at the surgical site. However, the gelatin glue group had a similar histopathological evaluation to the fibrin glue and control groups, but a quite different CSF leakage ratio. Therefore, we think that the relationship between the persistence and strength of the dural seal, and the histological properties of the tissue adhesives, will require examinations, besides histopathological analysis, to be properly understood.

The gelatin glue contains GA, which has the potential to be toxic in vivo. However, it is necessary to fix the tissue proteins and gelatin (through Schiff base formation) to enhance the glue's resistance to enzymatic degradation. The commercially available dural sealant $\mathrm{GRF}^{\oplus}$ contains $2.5 \%$ GA solution, while Bioglue $^{\circledR}$ contains a $10 \%$ GA solution. Both have high adhesive strength, but their applications are limited by late complications and adverse events possibly related to GA toxicity. ${ }^{27-30)}$ Our new gelatin glue consists of $1 \mathrm{wt} \%$, just one-tenth the volume of GA compared to that of Bioglue ${ }^{\circledast}$. In the present histological study, both the new gelatin glue and control groups showed no difference in the degree of inflammation present at the junction between the dura and brain tissue. In both cases, the junction consisted of dense and diffuse lymphocytic infiltrates (Table 2). Both groups also showed bony remodeling with no appreciable difference between the two groups. These results are consistent with a previous report showing that the cytotoxicity of the gel extract is lower than that of free GA, indicating that GA in the extract is partially bound to gelatin molecules. ${ }^{13)}$

Biological materials such as collagen and gelatin of cow origin carry the risk of the prion disease bovine spongiform encephalopathy (BSE). ${ }^{31)}$ However, the World Health Organization and World Organization for Animal Health both support the safety of gelatin because of the source material (skin and bone) and acidic processing needed to produce the gelatin. ${ }^{32)}$ The source of the gelatin used in this study and the manufacturing process of the gelatin granules are certified according to BSE safety regulations in the United States and European Union, both of which have a high level of safety requirements due to the transmission risk of Creutzfeldt-Jakob disease (the human equivalent of BSE). In addition, gelatin granules of bovine origin have recently been recertified as BSE-safe based on new European Union regulations. Thus, we believe that the gelatin glue would be safe for use in medical products.

The conclusions of this study are limited. In the evaluation of CSF leakage after operation, re-opening procedures of the previous incision over the craniotomy area could make a new CSF leakage, which may affect the CSF sealing rate between groups. Furthermore, the analysis of a small animal model may not accurately reflect the results that would be observed in a clinical setting with human patients. Studies on a larger animal model and comparison with a commercially available hydrogel sealant are recommended to further validate the new gelatin glue.

\section{Conclusion}

Our results suggest that the new gelatin glue may improve adhesion between the glue and dura, thus improving the safety and efficacy of dural closures. We believe the new gelatin glue may prove useful as an easy-to-use, safe, and effective adhesive for neurosurgical dural closure.

\section{Acknowledgment}

GUNZE Ltd., Kyoto provided the gelatin for this study 
and a grant to offset study costs. The Neurosurgery Research Laboratory at Nara Medical University have no financial or marketing interest in the materials or methods used, nor in any of the manufacturers mentioned in this report.

\section{Conflicts of Interest Disclosure}

There are no conflicts of interest disclosure.

\section{References}

1) Alleyne Jr CH, Cawley CM, Barrow DL, Poff BC, Powell MD, Sawhey AS, Dillehay DL: Efficacy and biocompatibility of a canine craniotomy model. J Neurosurg 88: 308-313, 1998

2) Boop FA, Chadduck WM: Silastic duraplasty in pediatric patients. Neurosurgery 29: 785-788, 1991

3) Cloward RB, Cunnigham EB: The use of gelatin sponge in prevention and treatment of cerebrospinal rhinorrhea. J Neurosurg 4: 519-525, 1947

4) Narotam PK, Van Dellen JR, Bhoola K, Radoo D: Experimental evaluation of collagen sponge as a dural graft. Br J Neurosurg 7: 635-641, 1993

5) Schadel A: [Experimental study of Gore-Tex in the treatment of the skull base.] (French) Rev Larygol Otol Rhinol (Bord) 111: 89-93, 1990

6) Jackson MR, Mc Phee MJ, Drohan WN, Alving BM: Fibrin sealant: current and potential clinical applications. Blood Coagul Fibrinolysis 7: 737-744, 1996

7) Sierra DH, Nissen AJ, Welch J: The use of fibrin glue in intracranial procedures: preliminary results. Laryngoscope 100: 360-363, 1990

8) Edward MSB, Boggan JE, Fuller TA: The laser in neurological surgery. J Neurosurg 59: 555-556, 1983

9) Dolenc VV: Effectiveness of fibrin glue for preventing postoperative extradural fluid leakage (comments). Neurol Med Chir (Tokyo) 37(12): 886-889; discussion 889-890, 1997

10) Nistor RF, Chiari FM, Maier H, Hehl K: The fixed combination of collagen with components of fibrin adhesive: a new hemostyptic agent in skull base procedures. Skull Base Surg 7: 23-30, 1997

11) Suzuki S, Ikada Y: Sealing effects of cross-linked gelatin. J Biomater Appl 27(7): 801-810, 2013

12) Ozisik PA, Inci S, Soylemezoglu F, Orhan H, Ozgen T: Comparative dural closure techniques: a safety study in rats. Surg Neurol 65: 42-47, 2006

13) Lasa CI, Kidd RR 3rd, Nunez HA, Drohan WN: Effect of fibrin glue and opsite on open wounds in DB/DB mice. J Surg Res 54: 202-206, 1993

14) Hellebrekers BW, Trimbos-Kemper GC, van Blitterswijk CA, Bakkum EA, Trimbos JB: Effects of five different barrier materials on postsurgical adhesion formation in the rat. Hum Reprod 15: 1358-1363, 2000

15) Cosgrove GR, Delashaw JB, Grotenhuis JA: Safety and efficacy of a novel polyethylene glycol hydrogel sealant for watertight dural repair. $J$ Neurosurg 106: 52-58, 2007

16) Boogaarts JD, Grotenhuis AJ, Bartels RH, Beems T: Use of a novel absorbable hydrogel for augmentation of dural repair: results of a preliminary clinical study. Neurosurgery 57(suppl 1): 146-151, 2005

17) Cosgrove GR, Delashaw JB, Grotenhuis JA, Tew JM, Van Loveren H, Spetzler RF, Payner T, Rosseau G, Shaffrey ME, Hopkins LN, Byrne R, Norbash A: Safety and efficacy of a novel polyethylene glycol hydrogel sealant for watertight dural repair. $J$ Neurosurg 106: 52-58, 2007

18) Grotenhuis JA: Costs of postoperative cerebrospinal fluid leakage: 1-year, retrospective analysis of 412 consecutive nontrauma cases. Surg Neurol 64: 490-493, 2005

19) Leng LZ, Brown S, Anand VK, Schwartz TH: "Gasket-seal" watertight closure in minimal-access endoscopic cranial base surgery. Neurosurgery $62(5$ suppl 2): 342-343, 2008

20) Than KD, Wang AC, Etame AB, Marca F, Park P: Postoperative management of incidental durotomy in minimally invasive lumbar spinal surgery. Minim Invasive Neurosurg 51: 263-266, 2008

21) Blackburn SL, Smyth MD: Hydrogel-induced cervicomedullary compression after posterior fossa decompression for Chiari malformation. J Neurosurg 106(Suppl 4): S302-S304, 2007

22) Mulder M, Crosier J, Dunn R: Cauda equina compression by hydrogel dural sealant after a laminotomy and discectomy: case report. Spine 34: E144-E148, 2009

23) Lee G, Lee CK, Bynevelt M: DuraSeal-hematoma: concealed hematoma causing spinal cord compression. Spine (Phila Pa 1976) 35(25): E1522-E1524, 2010

24) Brennan M: Fibrin glue. Blood Rev 5: 240-244, 1991

25) Muhammed G, Yoshimine T, Maruno M, Takemoto O, Hayakawa T: Topical application of fibrin adhesive in the rat brain: effects on different cellular elements of the wound. Neurol Res 19: 84-88, 1997

26) Toosie K, Gallego K, Stabile BE, Schaber B, French $\mathrm{S}$, de Virgilio C: Fibrin glue reduces intra-abdominal adhesions to synthetic mesh in a rat ventral hernia model. Am Surg 66: 41-45, 2000

27) Bingley JA, Gadner MA, Stafford EG, Mau TK, Pholner PG, Tam RK, Jalali H, Tesar PJ, O’Brien MF: Late complications of tissue glues in aortic surgery. Ann Thorac Surg 69(6): 1764-1768, 2000

28) Hata H, Takano H, Matsumiya G, Fukushima N, Kawaguchi N, Sawa Y: Late complication of gelatinresorcin-formalin glue in the repair of acute type A aortic dissection. Ann Thorac Surg 83(5): 1621-1626, 2007

29) Furst W, Banerjee A: Release of glutaraldehyde from an albumin-glutaraldehyde tissue adhesive causes 
significant in vitro and in vivo toxicity. Ann Thorac Surg 79: 1522-1529, discussion 1529; 2005

30) LeMairre SA, Carter SA, Won T, Wang X, Conklin LD, Cosellli JS: The threat of adhesive embolization: BioGlue leaks through needle holes in aortic tissue and prosthetic grafts. Ann Thorac Surg 80(1): 106-110, 2005

31) Will RG, Ironside JW, Zeidler M: A new variant of Creutzfeldt-Jakob disease in the UK. Lancet 347: 921-925, 1996

32) Grobben AH, Steele PJ, Somerville RA, Taylor DM:
Inactivation of the bovine spongiform encephalopathy (BSE) agent by the acid and alkaline processes used in the manufacture of bone gelatin. Biotechnol Appl Biochem 39: 329-338, 2004

Address reprint requests to: Ichiro Nakagawa, MD, PhD, Department of Neurosurgery, Nara Medical University, 840 Shijo-cho, Kashihara, Nara 634-8522, Japan. e-mail: nakagawa@nmu-gw.naramed-u.ac.jp 